\title{
The impact of R\&D and innovation on global supply chain transition: GTAP analysis on Japan's public R\&D investment
}

\author{
Michael C. Huang ${ }^{1} \cdot$ Ming-Huan Liou² $\cdot$ Yoko lwaki ${ }^{3}$
}

Accepted: 2 September 2020 / Published online: 19 September 2020

(c) Institute for Social and Economic Change 2020

\begin{abstract}
Policymaking for science, technology, and innovation (R\&D) is stepping into a new era in the twenty-first century within a highly integrated production network, making it more challenging to capture the impact of R\&D investment from an evidence-based approach. To unfold the paradox of the R\&D spillover effect spared in the global supply chain, we use computable general equilibrium model with the GTAP database v10 to analyze the impact of Japan's public R\&D investment to the world focus on key sectors of global supply chain, namely chemical and pharmaceutical, electronic equipment, machinery, and transportation equipment to examine its output, external trades, and welfare. The productivity parameters triggered by public R\&D investment are calibrated from the SciREX Policymaking Intelligent Assistance System-Economic Simulator (SPIAS-e). The simulation results show significant increase in Japan's output and export for chemical and pharmaceutical, electronic equipment, and transportation equipment. The GDP growth was stimulated by $0.6 \%$ and substantial welfare improvement by USD 78,000 million, while other countries such as Malaysia and Taiwan by $0.4-0.6 \%$. In contrast, the economic indicators of China reveal a negative impact, implying a structural change in the composition of the production network. It is notable to see a higher economic integration of Oceania within the region through its vibrant production and trades. The study provides comprehensive global analysis on production networks and insights for evaluating the R\&D investment spillover effects.
\end{abstract}

Keywords GTAP $10 \cdot$ Public R\&D investment $\cdot$ SPIAS-e · Global supply chain

JEL Classification C68 $\cdot \mathrm{O} 31 \cdot \mathrm{O} 32$

Michael C. Huang

michael-huang@spf.or.jp

1 The Ocean Policy Research Institute (OPRI), The Sasakawa Peace Foundation (SPF), 1-15-16

Toranomon, Minato-ku, Tokyo 105-8524, Japan

2 Industry, Science, and Technology International Strategy Center (ISTI), Industrial Technology Research Institute (ITRI), Hsinchu, Taiwan

3 SciREX Center, National Graduate Institute for Policy Studies (GRIPS), Tokyo, Japan 


\section{Introduction}

The creation of the science, technology, and innovation (STI) knowledge platform initiated by public R\&D investment could utilize the expansion of scientific facilities and related supportive equipment and human capital with the spillovers flow into entrepreneurship (Kuroda 2013). This concept urged the direction in Japan's 4th Basic Plan for STI, emphasizing the evidence-based research and indicators to assist the government's policymaking system on STI and R\&D investment. In the highly integrated global market, the production networks have naturally abolished tariff barriers for efficient manufacturing in the supply chain (Fugazza and Maur 2008). Nevertheless, the evidence-based research on other factors for manufacturing transition is scarce to provide a reference for the spillover effect that could attract more interest in this global supply chain analysis.

According to the Statistics Bureau of Japan (MIC 2019), since 2009, the R\&D expenditure in Japan has been steadily increased from 150 to 185 billion USD (Fig. 1), whereas the majority is contributed by the private sector. On the other hand, the R\&D expenditure share in GDP remains at the level of 3.5\%, which relatively higher than other average of OECD countries (2.4\%) except for South Korea (4.2\%). However, the government-led R\&D expenditure to GDP share has been at the low level of $0.5 \%$, lower than the average of OCED $(0.6 \%)$ and most developed countries, such as Korea (1.0\%), Germany $(0.8 \%)$, and US (0.7\%), respectively (METI 2019).

Comparing the volume of $R \& D$ expenditure, the scale of public investment is much smaller than private sectors; nevertheless, the public R\&D investment in basic science could generate more spillover effect to facilitate the productivity in multi-sector. Such $R \& D$ investment mostly presents in the form of the competitive research fund granted to research institutes and universities. Unlike the outcome from private R\&D investment usually turns to protected patent to ensure the profitability, public-funded research outcome could be publicized and shared with the society after a specific period (usually 5-year); thus, the policy cost-effectiveness could be examined more systematically (Kuroda et al. 2018).

The technology also accelerates the access of medicine through marketing on cyber platform seamlessly with affordability (Biswas 2014); the connectivity of medical service through electronic equipment in distant prescription may also speed up the application of information communication technology (ICT) and the pharmaceutical industry along with



Fig. 1 Japan's R\&D expenditure (1 USD=105 JPY) Source: Calculated by authors based on MIC (2019) and METI (2019) 
the global deregulation. It is inevitable that the demand for electronic equipment, machinery, and transport equipment would increase substantially, stressing the government to react appropriately to take plausible measures and science, technology, and innovation (STI) policy to improve economic growth and welfare.

\section{New form of the resilient global supply chain}

Since the 1990s, the foreign direct investment (FDI) outflow from Japan and other newly industrialized economies (NIEs) in Asia have contributed to regional production networks with substantial share global demand for electronic equipment, transport equipment, and machinery. The mushroomed free trade agreements in the 2000s also speeded up their independence. Therefore, the supply chain disruptions caused by natural disasters could make a significant impact on other countries without physical damage in cases of great earthquakes in Taiwan (1999), Japan (2011), and the floods in Thailand (2011).

Japan's 5th Science and Technology Basic Plan (Cabinet Office 2016) advocates that Japan should aspire to transfer from information society to "Society 5.0", which infers a human-centered society that balances economic advancement with the resolution of social problems by a system that highly integrates cyberspace and physical space. Such transition requires substantial input for ICT products for domestic infrastructure as implementation for more efficient and effective actualization of productivity in smart manufacturing and smart city development. To accommodate such transition, the domestic production may be stimulated again and such public investment for R\&D and innovation could also serve a positive shock with spillover effect to accelerate the production transition among the global supply chains.

The growing complexity in the global supply chain in logistics and intermediate inputs has made it challenging for a business to reduce the vulnerability of disruption (Christopher and Peck 2004), while the determination of production networks is the fractionalization between specialized components of manufacturing and exchange in the global supply chain (Baldwin 2013). Such a framework is continuously transiting intra- or inter-regionally from the competitiveness in the product innovation of the increasing capital intensity and upgrade, mostly in the electronic equipment, for their usage for communication and city renovation in transaction and transportation (Navarro et al. 2017).

The platform economy is contributed significantly by the rapidly spreading e-commerce since the 2000s with the support of ICT products such as personal computers and the internet. With the increasing popularity of the smartphone in the 2010s, the shared economy rephrased the business landscape worldwide with robust applications such as virtual shops, restaurants, and miscellaneous that highly depended on internet service with intensive input of electronic equipment. Such development does change not only the way of life but also stimulate the creation of innovation from a considerable small unit (Evans and Gawer 2016). While the significantly positive impact of R\&D investment on GDP growth and e-commerce have been testified (Anvari, and Norouzi 2016), it would be more desirable to see its spillover effect among sectors and region globally.

\section{The impact and spillover effect of public R\&D investment}

For emerging economies, manufacturing sectors require stable investment to build a smart society system. While impact assessment of possible mega natural disasters on Asian supply chains (Huang and Masuda 2020) and innovative financing framework for ASEAN 
countries (Huang et al. Forthcoming) have been widely discussed, there remain gaps for the spillover impact of R\&D investment. The research aims to provide an evidence-based approach to Japan's public R\&D investment to increase productivity and its impact on the integrated production networks. As the impact of the trade war between the US and China does not limit to the large economy but also to the emerging market (Carvalho, Azevedo, and Massuquetti 2019), to stabilize competitive production network is of importance than risk hedging. Furthermore, along with the new age after the coronavirus shock, the research expects to shed light on unfolding the potential collaboration.

Confronting the critics on government R\&D intervention may distort the market. Empirical studies in the Korean pharmaceutical industry provide a contrasting approach that government R\&D expenditure repairs the market failure for the smaller scale of venture firms (Choi and Lee 2017). The timing for investment in R\&D cluster formation also matters for welfare optimization before a considerable long time for technology to be commercialized from the laboratory. Therefore, government's role in long-term decision-making foresight for R\&D investment (Lee and Yang 2018) is critical with demonstration effect to the industrial development. Also, government R\&D expenditure could generate higher labor productivity growth with the flexibility (Dawid and Hellmann 2017; Coccia 2012); this evidence suggests the vibrant role initiated by the government to provide essential support in the target sector.

The innovation network serves significant factors for pharmaceutical sectors for new product development (Mazzola et al. 2015). The partnership and the flow of supply chain may receive more attention in the emerging market, where actions of small and mediansized enterprises (SMEs) toward innovation are also highly correlated with supply chain clusters (Ren et al. 2015). In such circumstances of uncertainty, the government's decision making may significantly affect the cluster's move and coordination following an evidencebased method to determine the specific sector for R\&D investment. While flexibility is desirable, industries that could actively respond would be more potential and resilient. The government expenditure on R\&D also shows the leading effect on private investment (Sussex et al. 2016). Such demonstrate behavior could result in a greater return, and the accumulated capital would have a direct impact on productivity.

Nevertheless, the spillover effect between firms does not show as significant as internal R\&D (Isaksson et al. 2016), implying the importance of public R\&D investment, which generates a high return in information technology could come with intertemporal knowledge spillovers (Miyagawa and Hisa 2013). The pharmaceutical industry operates with high risks for its costly $R \& D$ input; however, such risk could be pooled through public facilities under proper coordination between research institute, education system, and the private sectors. Japan's pharmaceutical industry was considered at a smaller scale compared with the US, but its financial condition has fewer constraints (Mahlich and RoedigerSchluga 2006). Its competitiveness in the deregulation accelerated by the Comprehensive Progressive Trans-Pacific Partnership (CPTPP) may be potentially strengthened (Kawasaki et al. 2019).

\section{The capture of R\&D impact}

After the burst of the bubble economy in Japan in the early 1990s, the R\&D capital is estimated more important than physical capital (Suzuki and Chida 2017), whereas it remains difficult to capture the impact and contribution of the R\&D to productivity. As Japan went through the economic stagflation, the cost-effectiveness of government expenditure 
became rather tightened due to the shrinking population in the super-aging society. Empirical evidence shows that the importance of public R\&D investment in educational institutes such as the university system for cutting-edge research (Becker 2015). Such investment provides the most spillover for the high-skilled human capital trained in the public order could also contribute to the productivity of the private sector. The evidence-based research thus becomes vital to allocate budget for R\&D and innovative investment.

$\mathrm{R} \& \mathrm{D}$, in many aspects, could foster the firm's production and marketing activities to meet the requirements. The intangible $R \& D$ investment contains the features of sunk cost, spillover, scalable, and synergies (Haskel and Westlake 2018). Such a measure of productivity improvement should be decomposed more specifically to generalize the R\&D contribution (Chan et al. 2014). However, the survey data of the firm-level will not satisfy the inquiry of R\&D effectiveness comprehensively. To capture the spillover effect of public R\&D investment, it would be indispensable to investigate the structural change of industry from the input-output table (Kuroda et al. 2018). The evolution of intermediate input implies the technology improvement; for instance, in 2010, less coal and iron input required for steel production than in 1995, representing the increase in productivity. Similar cases could also be found in the automobile sector, which needs more input of semiconductors and IC chips because of the development of ICT products.

The SciREX Policy Intelligence Assistance System (SPIAS) was constructed, affiliated with an economic simulator (SPIAS-e), which provides a 50-year projection of productivity parameters contributed by public R\&D investment. Such a system is based on the timeseries data and demographic trend sourced from Japan's input-output tables since 1995 for recursive Computable General Equilibrium (CGE) simulation. The R\&D policy option also derives the specification of tangible and intangible capital stock (Kuroda et al. 2018), and its application on technology improvement for renewable energy in Japan (Huang and Kim 2020). Despite the sophisticated R\&D foresight demonstration, given the constraint of SPIAS-e only for Japan's analysis, it is desirable to connect the system for a global-scale impact.

The paper proceeds as follows; the methodology section introduces the model structure and selected formula for the analysis. The data and scenarios section explains the data source, research scope, parameter setting, and calibration. In the section of simulation results, key economic indicators such as output, price, and the external trade are demonstrated in figures, along with the welfare analysis on GDP and welfare, followed by the concluding remarks and future perspectives.

\section{Methodology}

The computable general equilibrium (CGE) model has a long history in analyzing national and global trade income with the Global Trade Analysis Project (GTAP) model. Since its establishment in the 1990s, the complexity of the GTAP model continuously grows with more sectors and regions involved (Mensbrugghe 2013). The framework provides clear policy implications through key indicators such as the changes of output, prices, trade volume, as well as the impact analysis in the optimal level of the implementation of subsidy and tariff sectorally and simultaneously.

We apply a CGE model with the GTAP database version 10 to examine Japan's public R\&D investment and its spillover effect on other important players in the global supply chain. The GTAP database v10 consists of 65 sectors and 141 regions, accounting 
for worlds 98\% GDP and 92\% population as of the base year of 2014 (Aguiar et al. 2019). The composite of Japan's manufacturing and population began to have structural change with higher input of electronic equipment in communication, energy, and agriculture, resulting in more economic integration with the global supply chain. In this section, following Table 1, we introduce the parameters, variables, and formula used for the simulations based on Hertel (1996).

The GTAP model is widely used for trade analysis with informative implications for sectors, deficits, and welfare. The composite function of factor production, demand, output, and consumption could be derived as:

Composite factor production

$$
Y_{j, r, t}=b_{j, r}\left[\sum_{h} \beta_{h, j, r} F_{h, j, r, t}^{\left(\sigma_{j}^{f}-1\right) / \sigma_{j}^{f}}\right]^{\sigma_{j}^{f} /\left(\sigma_{j}^{f}-1\right)} \forall j, r, t
$$

Factor demand

Table 1 The parameters and variables in the model (selected) Source: Hertel (1996)

\begin{tabular}{|c|c|}
\hline$i, j$ & Sector \\
\hline$r, s, r r$ & Region \\
\hline$h$ & Factor (labor and capital) \\
\hline$t$ & Time period (in this model, $t=1$ ) \\
\hline \multicolumn{2}{|c|}{ Parameter } \\
\hline$b_{j, r}$ & Scale parameter in the production function \\
\hline$\beta_{h, j, r}$ & Share parameter in the production function \\
\hline$\alpha_{i, r}$ & Share parameter in the utility function \\
\hline$a x_{i, j, r}$ & Intermediate input requirement coefficient \\
\hline$\sigma_{i, r}^{m}, \sigma_{i, r}^{d}$ & Share par. in Armington function \\
\hline$\gamma_{i, r}$ & Scale par. in Armington function \\
\hline$\sigma_{j}^{f}$ & Substitution elasticity between factors (data retrieved from the GTAP database) \\
\hline$\sigma_{i}^{d}$ & Substitution elasticity between $D$ and $Q M$ (data retrieved from the GTAP database) \\
\hline$\sigma_{i}^{m}$ & Substitution elasticity between countries (data retrieved from the GTAP database) \\
\hline \multicolumn{2}{|c|}{ Variables } \\
\hline$Y_{j, r}$ & Composite factor \\
\hline$Z_{j, r}$ & Gross domestic output \\
\hline$X_{i, r}^{p}$ & Household consumption of the $i$-th good \\
\hline$F_{h, j, r}$ & Factor input \\
\hline$F_{h, j, r}^{0}$ & Input of factor of production at market price \\
\hline$p^{q}$ & Price of Armigton's goods \\
\hline$p^{f}$ & Factor price \\
\hline$S^{p}$ & Private saving \\
\hline$Q T_{i, r, s}$ & International shipping from the $r$-th region to the $s$-th region \\
\hline$Q E_{i, r}$ & Composite exports \\
\hline$Q M_{i, r}$ & Composite imports \\
\hline
\end{tabular}




$$
F_{h, j, r, t}=\left[\frac{b_{j, r}^{\left(\sigma_{j}^{f}-1\right) / \sigma_{j}^{f}} \beta_{h, j, r} p_{j, r, t}^{y}}{\left(1+\tau_{h, j, r}^{f}\right) p_{h, j, r, t}^{f}}\right]^{\sigma_{j}^{r}} Y_{j, r, t} \quad \forall h, j, r, t
$$

Gross domestic output transformation

$$
Z_{i, r, t}-Q T S_{i, r, t}=\theta_{i, r}\left[\xi e_{i, r} Q E_{i, r, t}^{\left(\sigma_{i}^{d}+1\right) / \sigma_{i}^{d}}+\xi d_{i, r} D_{i, r, t}^{\left(\sigma_{i}^{d}+1\right) / \sigma_{i}^{d}}\right]^{\sigma_{i}^{d} /\left(\sigma_{i}^{d}+1\right)} \forall i, r, t
$$

Household consumption

$$
X_{i, r, t}^{p}=\frac{\alpha_{i, r}}{p_{i, r, t}^{q}}\left(\sum_{h, j} p_{h, j, r, t}^{f} F_{h, j, r, t}-S_{r, t}^{p}-T_{r, t}^{d}\right) \quad \forall i, r, t
$$

Domestic goods demand

$$
D_{i, r, t}=\left[\frac{\gamma_{i, r}^{\left(\sigma_{i}^{d}-1\right) / \sigma_{i}^{d}} \delta d_{i, r} p_{i, r, t}^{q}}{p_{i, r, t}^{d}}\right]^{\sigma_{i}^{d}} Q_{i, r, t} \quad \forall i, r, t
$$

The government behavior in the model is unable to save but to impose direct taxes on the household to fill the gap between its consumption expenses $X_{i, r, t}^{g}$ and its other revenues from production tax $T_{j, r, t}^{z}$, import tariffs $T_{i, r, t}^{m}$, and export taxes $T_{i, r, t}^{e}$. The function is thereby derived as:

Direct tax

$$
T_{r, t}^{d}=\sum_{i} p_{i, r, t}^{q} x_{i, r, t}^{g}-\left(\sum_{j} T_{j, r, t}^{z}+\sum_{h, j} T_{h, j, r, t}^{f}+\sum_{i, s} T_{i, s, r, t}^{m}+\sum_{i, s} T_{i, r, s, t}^{e}\right) \forall r, t
$$

where $T_{r}^{d}=$ direct tax revenue; $T_{j, r}^{Z}=$ production tax revenue; $T_{h, j, r}^{f}=$ factor input tax revenue; $T_{i, r, s}^{e}=$ export tax revenue; $T_{i, r, s}^{m}=$ import tariff revenue. $p_{i, r, t}^{q}$ denotes the price of the Armington's (1969) composite good.

Based on the suggestions from the National Account System 2008 (UN 2009), the R\&D activities are accumulated in the capital stock, rather than in the intermediate good. Government investment is derived in the form of providing capital-use subsidy on the sectoral capital stock, for it is set as an immobile factor, so that the investment could be limited to the selected sector at the investment determined. Labor is set as mobile factor within region, so it could flow to other sector for profit optimization.

Factor input tax

$$
T_{h, j, r, t}^{f}=\tau_{h, j, r}^{f} p_{h, j, r, t}^{f} F_{h, j, r, t} \quad \forall h, j, r, t
$$

Factor tax rates

$$
\tau_{h, j, r}^{f}=T_{h, j, r}^{f 0} / F 0_{h, j, r}
$$


Further, the energy goods demand for the household $X_{i, r}^{p}$ are the function of the goods production function. The coefficient parameter of $a x_{i, j, r}$ denotes for the intermediate input coefficient, which shows the productivity improvement triggered by R\&D investment

$$
\begin{gathered}
X_{i, r}^{p}=\alpha_{i, r} \cdot \sum_{h, j}\left(F F_{h, i, j}-s_{r}^{p}-T_{r}^{d}\right) / p_{i, r}^{q} \\
a x_{i, j, r}=X_{i, j, r}^{0} / Z_{i, r}^{0}
\end{gathered}
$$

The external trade functions derive as follows:

Import flow function

$$
Q T_{i, s, r, t}=\left[\frac{\omega_{i, r}^{\left(\sigma_{i}^{m}-1\right) / \sigma_{i}^{m}} \psi_{i, s, r} p_{i, r, t}^{q m}}{\left(1+\tau_{i, s, r}^{e}\right) p_{i, s, r, t}^{q t} \varepsilon_{s, r, t}+\tau_{i, s, r}^{s} p_{t}^{q q t} \varepsilon_{R O W, r, t}\left(1+\tau_{i, s, r}^{m}\right)}\right]^{\sigma_{i}^{m}} Q M_{i, r, t} \quad \forall i, s, r, t
$$

Composite exports supply function

$$
Q E_{i, r, t}=\left[\frac{\theta_{i, r}^{\left(\sigma_{i}^{d}+1\right) / \sigma_{i}^{d}} \xi e_{i, r}\left(1+\tau_{i, r}^{z}\right) p_{i, r, t}^{z}}{p_{i, r, t}^{q e}}\right]^{-\sigma_{i}^{d}}\left(Z_{i, r, t}-Q T S_{i, r, t}\right) \quad \forall i, r, t
$$

Composite import demand function

$$
Q M_{i, r, t}=\left[\frac{\gamma_{i, r}^{\left(\sigma_{i}^{d}-1\right) / \sigma_{i}^{d}} \delta m_{i, r} p_{i, r, t}^{q}}{p_{i, r, t}^{q m}}\right]^{\sigma_{i}^{d}} Q_{i, r, t} \quad \forall i, r, t
$$

Finally, the welfare function is determined by the utility function associate with expenditure function (cost minimization expenditure attaining a utility level), implying the consumption level variation from the output price changes.

Utility function:

$$
\begin{gathered}
U U_{r}^{0}=\prod_{i}\left(X_{i, r}^{p 0}\right)^{\alpha_{i, r}} \\
\operatorname{ep}\left(p^{q}, U U\right)=\min _{X P}\left\{p^{q} \cdot \mid U U\left(X^{p}\right)=U U\right\}
\end{gathered}
$$

The welfare (WF) indicates the utility difference $\left(U U^{0}\right)$ before and $\left(U U^{1}\right)$ after the policy intervention as equivalent variation $(\mathrm{EV})$.

$$
\mathrm{WF}=\mathrm{ep}\left(p^{q 0}, U U^{1}\right)-\mathrm{ep}\left(p^{q 0}, U U^{0}\right)
$$




\section{Data and scenarios}

\section{Sector and region category}

To analyze the key sectors of the global supply chain, we aggregate 14 regions from the base year of 2014 to interpret the impact on the economic indicators specifically (Table 2), the breakdown details could refer to "Appendix" (Table 5). The sectors and regions are categorized based on their representativeness in the supply chain. Because of the trade gravity, we tend to use a single country in Asia to review its impact, while aggregations were made for other regions for simplicity.

\section{Scenario: Japan's public R\&D investment}

For the R\&D investment scenario, following the definition and suggestion of SNA2008 (UN 2009), the R\&D investment is used for policy simulations as a capital-use subsidy to increase capital accumulation in the capital stock. According to Kuroda, Ikeuchi, Hara, et al. (2018), the productivity change is assumed to be actualized after a 5-year R\&D investment for a $20 \%$ more public R\&D expenditure on basic science. Based on the statistics of 2014, the public R\&D investment was categorized into five fields. We provide the policy shock of a total USD 61,743 million (5-year amount in present value), equivalent to $2.82 \%$ of Japan's total capital stock as a capital-use investment (Table 3 ).

The improvement rates are calibrated from SPIAS-e simulator on changes in the price of capital goods (PSK). In Table 4, we aggregate 10 sectors from 165 sectors classified in GTAP database, and 93 sectors classified in SPIAS-e (Table 7) to accommodate this study. The scenario shows that productivity increases in some sectors such as Agriculture (AGR) by $1 \%$, Chemicals and pharmaceuticals (CHP) by $2.7 \%$, and Energy (ENG) by $0.85 \%$. Nevertheless, with the consideration of shrinking population parameter setting in SPIAS-e (Kuroda et al. 2018), sectors such as Metal and steel (MET), Electronic equipment (EEP), Service (SRV) could not gain productivity improvement despite the substantial increase in

Table 2 Region aggregation Source: By authors based on GTAP v10

\begin{tabular}{ll}
\hline Region & Description \\
\hline Japan & Japan \\
Korea & South Korea \\
China & China and Hong Kong \\
Taiwan & Taiwan \\
Thailand & Thailand \\
Malaysia & Malaysia \\
Indonesia & Indonesia \\
Vietnam & Vietnam \\
R_ASEAN & Rest of the ASEAN \\
S_Asia & Rest of Asia \\
Oceania & Oceania \\
USMCA & North America \\
Europe & Europe \\
ROW & Rest of the world \\
\hline
\end{tabular}


Table 3 5-year Public R\&D investment in basic science (Unit: USD million) Source: Calculated by authors based on the Ministry of General Affairs (2019)

\begin{tabular}{lccccc}
\hline Category & Intangible & Tangible & Sum & Total (1.2 times) & Capital share (\%) \\
\hline Life & 20,528 & 3991 & 24,520 & 61,743 & 2.82 \\
Information & 4380 & 904 & 5284 & & \\
Materials & 4288 & 799 & 5087 & \\
Energy & 1996 & 981 & 2977 & \\
Others & 13,129 & 10,747 & 23,876 & & \\
\hline
\end{tabular}

Base year: 2014; 1 USD=105 JPY

Table 4 Productivity changes in Japan by public R\&D investment Source: Authors' assumption based on SPIAS-e

\begin{tabular}{llc}
\hline Abbreviation & Sector & PSK change (\%) \\
\hline AGR & Agriculture & +1.01 \\
ENG & Energy & +0.85 \\
MAN & Manufacture & -0.40 \\
MET & Metal and steel & -4.00 \\
CHP & Chemicals and pharmaceutical & +2.68 \\
EEP & Electronic equipment & -1.57 \\
MCH & Machinery & +0.41 \\
TEQ & Transport equipment & +0.52 \\
TRS & Transportation service & +0.68 \\
SRV & Service & -4.08 \\
\hline
\end{tabular}

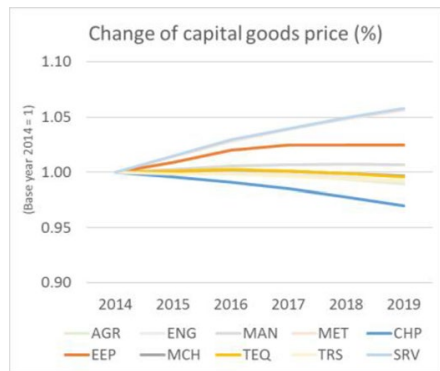

public R\&D investment by $20 \%$, implying the technology transition in Japan. However, the spillover effect of public R\&D investment could contribute to output, external trades, and social welfare.

\section{Simulation results}

\section{Output and price}

We conduct a 5-year public R\&D investment in a static simulation. Japan's output shows an increase in most of the sectors, especially for ENG (7.2\%), CHP (5.5\%), TEQ (4.1\%), AGR (3.5\%) and EEP (3.1\%) (Fig. 2). In comparison, there are only little growth for MCH $(0.6 \%)$ and decrease for TRS $(-1.0 \%)$ and SRV $(-0.9 \%)$ partially due to the shrinking population. Interestingly, the output of EEP increases substantially despite lower productivity. The overall technology installation for "Society 5.0" promoted in Japan since 2011 could explain the massive demand in all manufacturing, transportation, and service sectors. Regarding the price change, significant increases are found in MET (4.7\%) and AGR (2.6\%), while CHP shows a decrease of $0.4 \%$, indicating the technology advancement for this sector.

When looking from a global perspective (Fig. 3), we focus on four sectors with high interdependence on regional networks, namely chemical and pharmaceutical (CHP), electronic equipment (EEP), machinery $(\mathrm{MCH})$, and transportation equipment (TEQ). The productivity increase has led the different consequences. For CHP, Indonesia, Vietnam, 




Fig. 2 Changes of output and prices in Japan

10.0

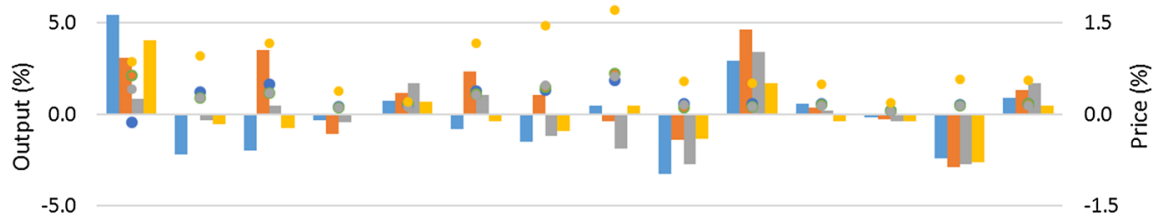

$-10.0$

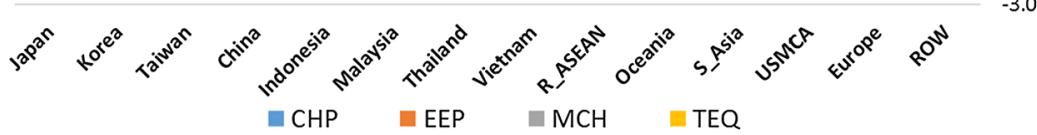

Fig. 3 Changes in output and prices

the Rest of Asia, Oceania, and the Rest of World show growth of 1-3\%, while other regions show a decrease, implying a less regional integration for the CHP sector. For EEP, Taiwan, Oceania, Malaysia, Indonesia, and Thailand also show a vibrant increase by $2-5 \%$, indicating their growing integration. On the other hand, Korea, China, Vietnam, the Rest of ASEAN, and Europe show a decrease. The change could refer that the production networks caused by the productivity growth in Japan could substitute the output from China.

The output growth of MCH for Japan is at a relatively low level of $0.8 \%$, while Taiwan, Indonesia, Malaysia, Oceania, and the Rest of World have higher output growth by $1-4 \%$, indicating a transition of MCH production networks. TEQ sectors have been Japan's competitive sectors; the output growth of $4 \%$ shows a strong supply ability, whereas other regions only show little change, while the Rest of ASEAN and Europe show a decrease of $1-3 \%$. It is interesting to see significant growth from Oceania, especially in EEP. Although the volume is relatively smaller than other products, the drastic growth shows that Oceania is playing a more important role in the production networks.

The price changes imply the affordability of improved technology. The public R\&D expenditure in Japan has caused a price decrease $0.4 \%$ in CHP sector, while other key sectors range steadily from 1 to $2 \%$. In other regions, output price of TEQ has increased by $4-6 \%$ in Korea, Taiwan, Malaysia, Thailand, and Vietnam, indicating that 
the difficulty for these regions to accommodate the technology advancement in TEQ. However, higher prices in Electronic equipment still stimulate the regional output, especially in Taiwan, Malaysia, and Thailand. The price change is rather steady for Oceania with a higher potential to have production integration with Japan. In other regions with distance such as USMCA and Europe, the change of output and price are very small. Overall speaking, Japan's public R\&D investment could help deepen the production networks with Oceania, Taiwan, Malaysia, Indonesia, Thailand, whereas the impact with Korea and China is insignificant.

\section{External trade}

To further explain the composite of trade structure, we demonstrate an external trade transition with the change rate of trade volume (Fig. 4). The productivity increase in Japan would strengthen its export in the target sectors of CHP (9.1\%), TEQ (6.5\%), $\mathrm{MCH}(3.7 \%)$, and EEP (3.6\%). Oceania also shows the same trend. Other export growth could be found in Taiwan, and Indonesia also for EEP. However, the export in most regions shows a decrease of $1-3 \%$, especially in CHP. Regarding the import change, the decrease in almost all regions indicates that the domestic demand does not change significantly, but the composite of trading partner may change, which requires further look into the breakdown. Taiwan shows a slight increase in electronic equipment imports may indicate that their role in the production network. Such transition infers that the productivity improvement in Japan could satisfy its output and global market expansion.

Export

30.0

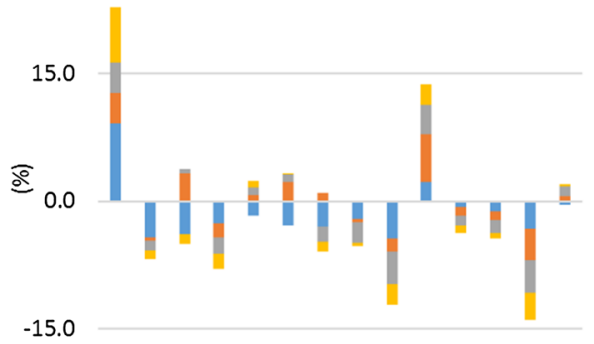

$-30.0$

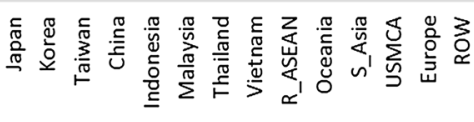

- $\mathrm{CHP}$
Import
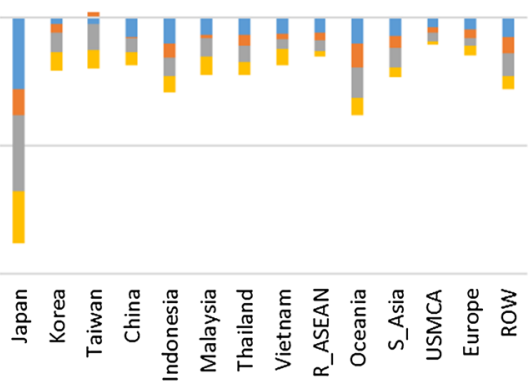

$\mathrm{MCH} \quad \mathrm{TEQ}$

Fig. 4 Changes on external trades 


\section{Change rate on trade volume}

\section{Chemical and pharmaceutical (CHP)}

The breakdowns of trade volume could provide more details to identify the change of trading partners (Fig. 5). For the CHP, the trade volume with Japan in almost all regions increases by $7-10 \%$. The trade volume of Oceania with other regions has a great growth of $3-4 \%$ in Europe, USMCA, Malaysia, the Rest of ASEAN, and the Rest of the world, implying that Oceania and Japan could have complementary relations in the CHP.

\section{Electronic equipment (EEP)}

Consistent with the fluctuations of the output, a significant increase in trade volume in the EEP sector indicates the high correlation of production networks between Japan, Taiwan, Malaysia, and Oceania for 2-8\% (Fig. 6). Notably, the trade volume of EEP for intercontinental relation has higher demand from the Asia-Pacific region, such as Europe and USMCA. With worthy of attention, the trade volume of China, South Korea, and Europe with all the regions also drops substantially by 3-6\%, implying that the R\&D investment in Japan might lead a switch on the map for the global supply chain.

\section{Machinery (MCH)}

Japan's productivity growth in the $\mathrm{MCH}$ sector strengthens its trade volume with all the regions by $3-6 \%$, and the domestic demand could also be satisfied by itself (Fig. 7). Similar to the results in Electronic equipment, the substantial decrease in trade volume in $\mathrm{MCH}$ from China, Europe, and the Rest of ASEAN indicate that the structural change of the demand. If advanced machinery equipment could be accessed from Japan at affordable prices, the market share would reflect rapidly. Notably, the increase in South Korea, China, and Europe shows an ambition to secure their capacity in global supply chains because $\mathrm{MCH}$ serves the base for all manufacturing.

\section{Chemical \& pharmaceutical}

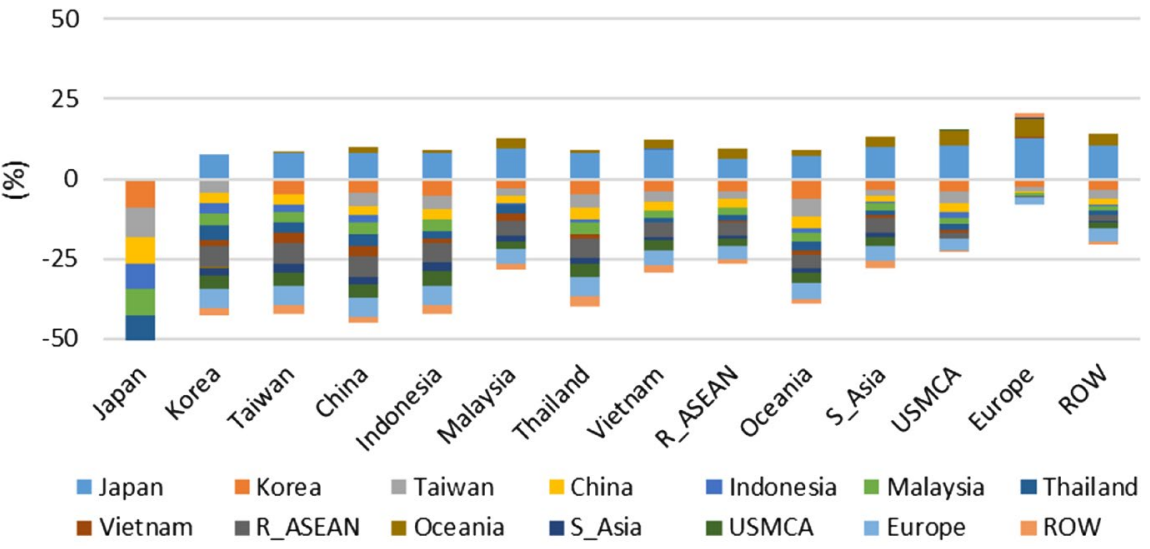

Fig. 5 Changes on trade flow of chemical and pharmaceutical 


\section{Electronic equipment}

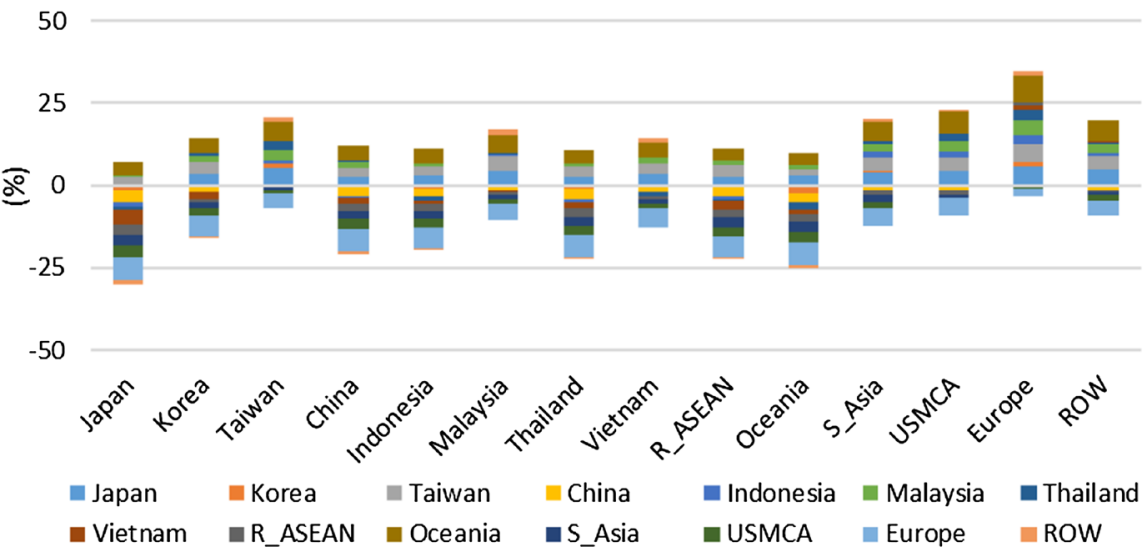

Fig. 6 Changes on trade flow of electronic equipment

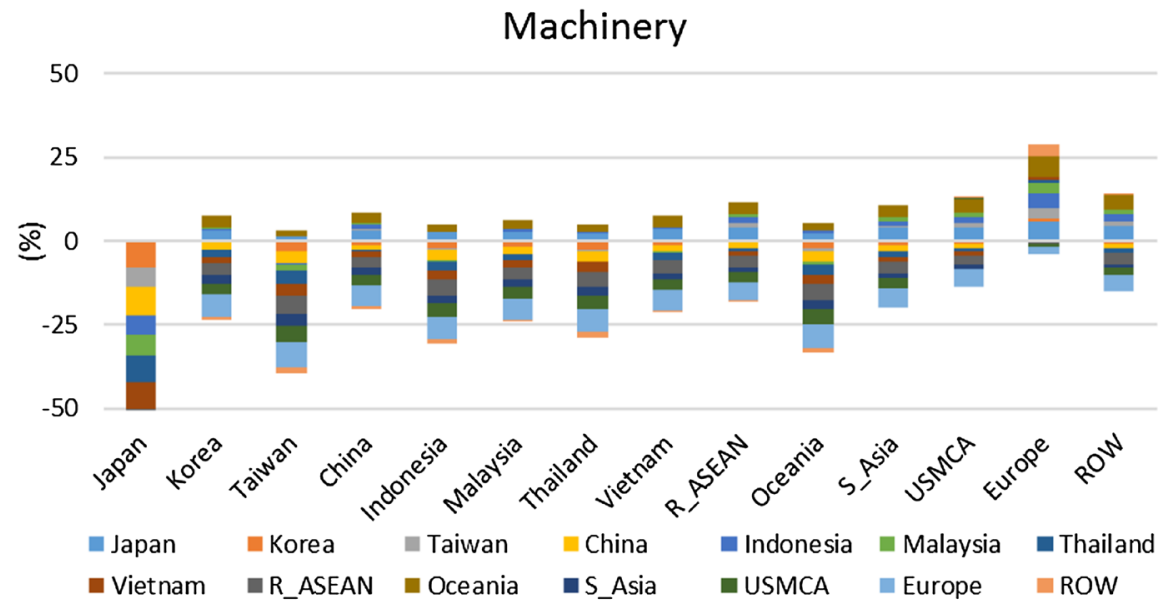

Fig. 7 Changes on trade flow of machinery

\section{Transport equipment (TEQ)}

After the Great East Japan Earthquake and the Thai Flood in 2011, the global supply chain for TEQ already occurred a structural change to hedge the disruption risk from a single country. Comparing with other sectors, the trade volume of TEQ with Japan still shows a significant increase in all regions by 3-7\% (Fig. 8). The demand for TEQ in South Korea, China, the Rest of ASEAN, and Europe is still increasing, and therefore the supply of Japan may provide the most cost-effective component assisting the industry. Such transition also enables Japan to accelerate the TEQ for the next generation, such as a more affordable hybrid engine and the auto-driving system to maintain its competitiveness and production and application. 


\section{Transport equipment}

50

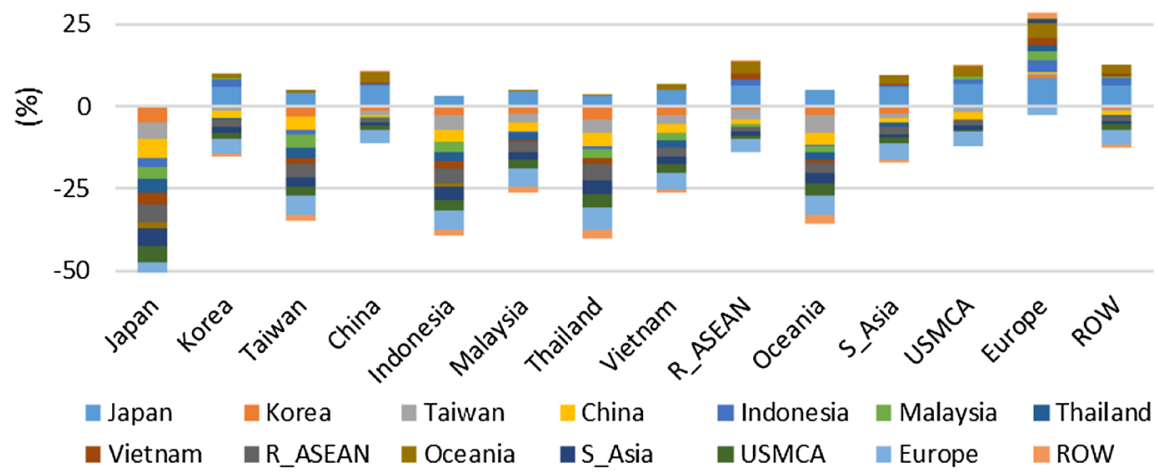

Fig. 8 Changes on trade flow of transport equipment

\section{Welfare analysis}

\section{GDP and social benefit}

We analyze the welfare from dimensions of GDP growth and the social benefit change, which is illustrated in the form of equivalent variations (EV) after the policy shock (Fig. 9). The public R\&D investment in Japan with productivity parameters could increase Japan's GDP growth by $0.6 \%$ thanks to the substantial growth in output and export. It is notable that the GDP grows in Taiwan $(0.6 \%)$, Malaysia $(0.4 \%)$, and Vietnam $(0.1 \%)$, implying the spillover effect on the regional production network. In contrast, South Korea, China, Europe, and the Rest of ASEAN show a GDP decrease by $0.4-1 \%$, inferring the output and import substitute in the new structure of the supply chain led by Japan.

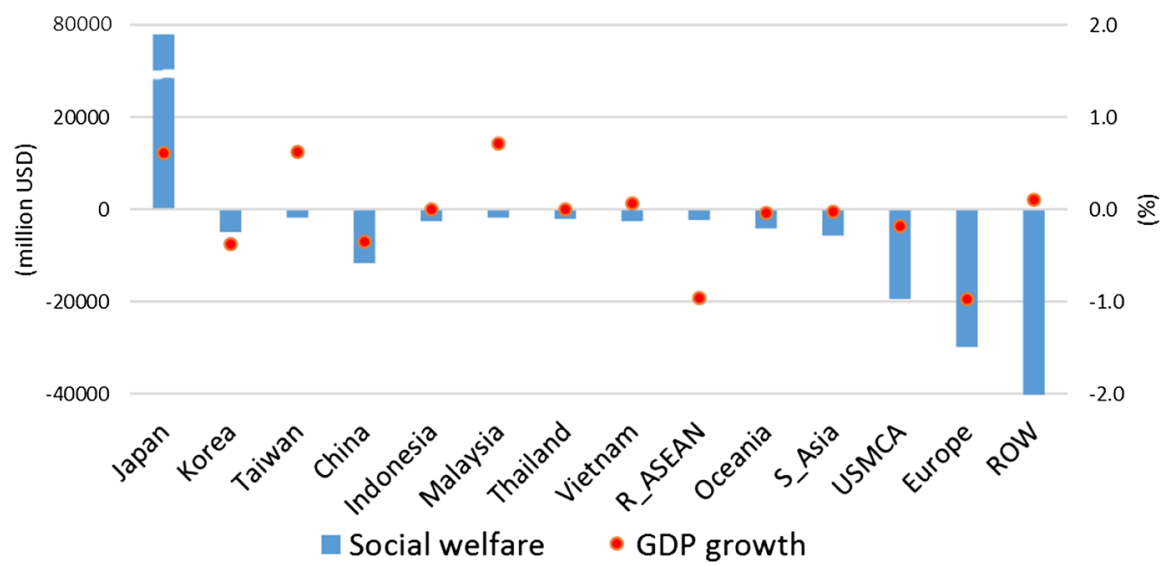

Fig. 9 Change on GDP growth and social benefit 
The determination of social benefit relies on the output price and household consumption under policy intervention. The productivity improvement triggered by Japan's R\&D expenditure substantially decreases the output price of target sectors, making greater affordability both domestically and globally. The social benefit of Japan shows a substantial increase of 78,250 million USD; however, the fiscal costs caused by R\&D expenditure may worsen Japan's deficit with a financial burden. Regions with GDP growth also suffer a bit worse-off social benefit due to the higher output prices in South Korea, Taiwan, Oceania, and ASEAN states for the similarity of the export-orientated sector in the regional production network. Among all, China, USMCA and Europe fall significantly in both GDP and social benefit, indicating the higher level of regional integration and diversification of "World Factory" from one single country to multiple sources.

\section{Conclusions}

\section{Discussion}

Evaluating the R\&D impact on the supply chain has been an important aim for the government in STI policymaking in an evidence-based approach. We applied a CGE model with the GTAP v10 database on four key sectors of chemical \& pharmaceutical, electronic equipment, machinery, and transport equipment to examine their spillover effect on global supply chain and economic impact. The calibration of capital price changes sourced from SPIAS-e has enabled us to capture the productivity change and its spillover effect under the public R\&D investment in basic science. Such methodology is innovative to unfold the projection of R\&D impact comprehensively on a global scale.

The simulation results show that Japan's output and export on target sectors could substantially increase, contributing GDP growth by $0.6 \%$, and substantial social benefit improvement. Moreover, other countries in the region, such as Malaysia, Indonesia, Thailand, Oceania, and Taiwan, will also be benefited from output and GDP growth. The supply chain integration shows the highest integration in the Electronic equipment sector, and the structural change of trade reveals for China and Oceania in the trade volume breakdown. Oceania shows a significant increase in output and trades with Japan as a new vibrant role in the production network. In contrast, the decreased output and trades of China imply the replacement of its position in the global supply chain.

For achieving the target of Society 5.0 in Japan under the circumstance of super-aging society and shrinking population, the advancement of productivity would be a critical issue for STI policy making for public R\&D investment. The simulation results in this study provided quantified consequences in chemical and pharmaceutical, electronic, and transportation equipment sectors, indicating the massive demand for Japan's medical service, smart vehicles and other infrastructure. The notable import of Japan's product also implies the R\&D lead gap and its competitiveness, providing other partner countries to set best R\&D investment strategy in response to Japan for collaboration.

\section{Research limitation and future perspective}

The research provides broad policy implications of public R\&D investment in a globalscale analysis with economic indicators and welfare change interpretation. These insights could provide an informative reference for government resource allocation toward the 
transition of markets and production networks. Although the GTAP model demonstrates a straight-forward policy intervention assessment, the assumption of 5-year public R\&D investment and its actualization and addition on overall capital stock may oversimplify the issue due to the intertemporal time-lag in innovation application. Therefore, a recursive model would be recommended to fill the gap of the dynamic approach.

These preliminary results could serve as evidence to raise awareness of countries in the production network for constructing a multi-region R\&D investment database. Moreover, the parameters of productivity improvement are only limited in Japan due to the single source of SPIAS-e. In the real world, R\&D and innovation are taking place in all regions simultaneously. The R\&D data infrastructure for many other countries is a desirable input to form a clearer picture of inclusive growth expects to contribute to economic integration and resilience for the global supply chain.

\section{Appendix}

See Tables 5, 6 and 7.

Table 5 Region categories from GTAP v10

\begin{tabular}{|c|c|}
\hline Region & GTAP regions \\
\hline Japan & Japan \\
\hline Korea & South Korea \\
\hline China & China; Hong Kong \\
\hline Taiwan & Taiwan \\
\hline Thailand & Thailand \\
\hline Malaysia & Malaysia \\
\hline Indonesia & Indonesia \\
\hline Vietnam & Vietnam \\
\hline R_ASEAN & Brunei; Cambodia; Laos; Philippines; Singapore \\
\hline S_Asia & $\begin{array}{l}\text { Mongolia; Rest of Asia; Rest of Southeast Asia; Bangladesh; India; Nepal; Pakistan; Sri } \\
\text { Lanka; Rest of South Asia }\end{array}$ \\
\hline Oceania & Australia; New Zealand; Rest of Oceania \\
\hline USMCA & Canada; USA; Mexico \\
\hline Europe & $\begin{array}{l}\text { Austria; Belgium; Cyprus; Czech Republic; Denmark; Estonia; Finland; France; Germany; } \\
\text { Greece; Hungary; Iceland; Italy; Latvia; Lithuania; Luxembourg; Malta; Netherlands; } \\
\text { Poland; Portugal; Slovakia; Slovenia; Spain; Sweden; United Kingdom; Switzerland; } \\
\text { Norway; Rest of EFTA; Albania; Bulgaria; Belarus; Croatia; Romania; Russian Federation; } \\
\text { Ukraine; Rest of Eastern Europe; Rest of Europe }\end{array}$ \\
\hline ROW & $\begin{array}{l}\text { Rest of North America; Argentina; Bolivia; Brazil; Chile; Colombia; Ecuador; Paraguay; Peru; } \\
\text { Uruguay; Venezuela; Rest of South America; Costa Rica; Guatemala; Honduras; Nicaragua; } \\
\text { Panama; El Salvador; Rest of Central America; Dominican Republic; Jamaica; Puerto Rico; } \\
\text { Trinidad and Tobago; Caribbean; Kazakhstan; Kyrgyzstan; Rest of Former Soviet Union; } \\
\text { Armenia; Azerbaijan; Georgia; Bahrain; Iran Islamic Republic of; Israel; Jordan; Kuwait; } \\
\text { Oman; Qatar; Saudi Arabia; Turkey; United Arab Emirates; Rest of Western Asia; Egypt; } \\
\text { Morocco; Tunisia; Rest of North Africa; Benin; Burkina Faso; Cameroon; Cote d' lvoire; } \\
\text { Ghana; Guinea; Nigeria; Senegal; Togo; Rest of Western Africa; Central Africa; South } \\
\text { Central Africa; Ethiopia; Kenya; Madagascar; Malawi; Mauritius; Mozambique; Rwanda; } \\
\text { Tanzania; Uganda; Zambia; Zimbabwe; Rest of Eastern Africa; Botswana; Namibia; South } \\
\text { Africa; Rest of South African Customs; Rest of the world }\end{array}$ \\
\hline
\end{tabular}







Table 7 Aggregation of sectors from SPIAS-e classification

Sector Original classification in SPIAS-e

AGR Agriculture (Main products, ICT activity); Agriculture (Intra-firm R\&D activity)

ENG Mining (Main products, ICT activity); Mining (Intra-firm R\&D activity); Petroleum, coal (Main products); Petroleum, coal (Intra-firm ICT activity); Petroleum, coal (Intra-firm R\&D activity); Energy manufacturing (Main products); Energy manufacturing (Intra-firm ICT activity); Energy manufacturing (Intra-firm R\&D activity); R\&D Ecology, energy (Public, non-profit); R\&D Ecology, energy (Industry)

MAN Food (Main products); Food (Intra-firm ICT activity); Food (Intra-firm R\&D activity); Synthetic (Main products); Synthetic (Intra-firm ICT activity); Synthetic (Intra-firm R\&D activity); Pulp, paper (Main products); Pulp, paper (Intra-firm ICT activity); Pulp, paper (Intra-firm R\&D activity); Miscellaneous manufacturing (Main products); Miscellaneous manufacturing (Intra-firm ICT activity); Miscellaneous manufacturing (Intra-firm R\&D activity)

MET Material (Main products); Material (Intra-firm ICT activity); Material (Intra-firm R\&D activity); R\&D Materials (Public, non-profit); R\&D Materials (Industry)

CHP Chemical (Main products); Chemical (Intra-firm ICT activity); Chemical (Intra-firm R\&D activity)

EEP Fibre-optical cable (Main products); Fibre-optical cable (Intra-firm ICT activity); Fibre-optical cable (Intra-firm R\&D activity); Semiconductor manufacturing (Main products); Semiconductor manufacturing (Intra-firm ICT activity); Semiconductor manufacturing (Intra-firm R\&D activity); Communication devices (Main products); Communication devices (Intra-firm ICT activity); Communication devices (Intra-firm R\&D activity); Computing equipment (Main products); Computing equipment (Intra-firm ICT activity); Computing equipment (Intra-firm R\&D activity); Semiconductor devices (Main products); Semiconductor devices (Intra-firm ICT activity); Semiconductor devices (Intra-firm R\&D activity); Electronic component (Main products); Electronic component (Intra-firm ICT activity); Electronic component (Intra-firm R\&D activity); Software (Main products); Software (Intra-firm R\&D activity); Information Management (Main products); Information Management (Intra-firm R\&D activity); Internet (Main products); Internet (Intra-firm R\&D activity)

MCH Machinery (Main products); Machinery (Intra-firm ICT activity); Machinery (Intra-firm R\&D activity); Electronic devices (Main products); Electronic devices (Intra-firm ICT activity); Electronic devices (Intra-firm R\&D activity); Robot (Main products); Robot (Intra-firm ICT activity); Robot (Intra-firm R\&D activity); Precise machinery (Main products); Precise machinery (Intrafirm ICT activity); Precise machinery (Intra-firm R\&D activity)

TEQ Heavy machinery, transportation equipment (Main products); Heavy machinery, transportation equipment (Intra-firm ICT activity); Heavy machinery, transportation equipment (Intra-firm R\&D activity)

TRS Transportation (Main products); Transportation (Intra-firm ICT activity); Transportation (Intrafirm R\&D activity)

SRV Construction (Main products); Construction (Intra-firm ICT activity); Construction (Intra-firm R\&D activity); Communication (Main products); Communication (Intra-firm ICT activity); Communication (Intra-firm R\&D activity) Commerce (Main products); Commerce (Intra-firm ICT activity); Commerce (Intra-firm R\&D activity) Medical, welfare services (Main products); Education (Main products); R\&D Life science (Public, non-profit); R\&D Information communication (Public, non-profit); R\&D Miscellaneous (Industry); R\&D Life science (Industry); R\&D Miscellaneous (Industry); Miscellaneous service (Main products); Miscellaneous service (Intra-firm R\&D activity)

\section{References}

Aguiar A, Chepeliev M, Corong EL, McDougall R, van der Mensbrugghe D (2019) The GTAP data base: version 10. J Glob Econ Anal 4(1):1-27. https://doi.org/10.21642/jgea.040101 af

Anvari RD, Norouzi D (2016) The impact of E-commerce and R\&D on economic development in some selected countries. Procedia Soc Behav Sci 229:354-362. https://doi.org/10.1016/j.sbspro.2016.07.146 
Armington PS (1969) A theory of demand for products distinguished by place of production (Une theorie de la demande de produits differencies d'apres leur origine) (Una teoria de la demanda de productos distinguiendolos segun el lugar de produccion). Staff Papers - International Monetary Fund 16(1):159

Baldwin R (2013) Global supply chains: why they emerged, why they matter, and where they are going. In: Elms D, Low P (eds) Global value chains in a changing world, WTO, Geneva/TFCTN. https:// doi.org/10.30875/3c1b338a-en

Becker B (2015) Public R\&D policies and private R\&D investment: a survey of the empirical evidence. J Econ Surv 29(5):917-942. https://doi.org/10.1111/joes.12074

Biswas K (2014) Pharma's prescription. Academic Press, Cambridge. https://doi.org/10.1016/c2012 $-0-03159-6$

Cabinet Office (2016) Society 5.0, science and technology policy. Council for science, technology and innovation, Cabinet Office, The Government of Japan. https://www8.cao.go.jp/cstp/english/socie ty5_0/index.html

Carvalho M, Azevedo A, Massuquetti A (2019) Emerging countries and the effects of the trade war between US and China. Economies 7(45):1-21. https://doi.org/10.3390/economies7020045

Chan FTS, Nayak A, Raj R, Chong AYL, Manoj T (2014) An innovative supply chain performance measurement system incorporating Research and Development (R\&D) and marketing policy. Comput Ind Eng. https://doi.org/10.1016/j.cie.2013.12.015

Choi J, Lee J (2017) Repairing the R\&D market failure: public R\&D subsidy and the composition of private R\&D. Res Policy 69:64-70. https://doi.org/10.1016/j.respol.2017.06.009

Christopher M, Peck H (2004) Building the resilient supply chain. Int J Logist Manag 15(2):1-14. https ://doi.org/10.1108/09574090410700275

Coccia M (2012) Political economy of R\&D to support the modern competitiveness of nations and determinants of economic optimization and inertia. Technovation 32(6):370-379. https://doi. org/10.1016/j.technovation.2012.03.005

Dawid H, Hellmann T (2017) R\&D investments under endogenous cluster formation. SSRN Electronic Journal. Bielefeld Working Papers in Economics and Management No. 04-2016 https://doi. org/10.2139/ssrn.2747877

Evans PC, Gawer A (2016) The rise of the platform enterprise a global survey. The center for global enterprise. The emerging platform economy series no. 1. https://www.thecge.net/app/uploa ds/2016/01/PDF-WEB-Platform-Survey_01_12.pdf

Fugazza M, Maur JC (2008) Non-tariff barriers in CGE models: How useful for policy? J Policy Model 30(3):475-490. https://doi.org/10.1016/j.jpolmod.2007.10.001

Haskel J, Westlake S (2018) Capitalism without capital: the rise of the intangible economy. Princeton University Press, Princeton. https://doi.org/10.2307/j.ctvc77hhj

Hertel T (ed) (1996) Global trade analysis: modeling and applications. Cambridge University Press, Cambridge. https://doi.org/10.1017/CBO9781139174688

Huang M, Kim C (2020) Investigating cost-effective policy incentives for renewable energy in Japan: a recursive CGE approach for an optimal energy mix. Singap Econ Rev. https://doi.org/10.1142/ S0217590820430067

Huang M, Masuda A (2020) How do production networks affect the resilience of firms to economic and natural disasters: a methodological approach and assessment in Japan, Taiwan and Thailand. In: Anbumozhi V, Kimura F, Thangavelu S (eds) Supply chain resilience. Springer, Singapore, pp 77-108. https://doi.org/10.1007/978-981-15-2870-5_4

Huang M, Tanaka H, Yoshioka N (Forthcoming) Design for global supply chain disaster risk financing: examining cost-effective industrial policy for ASEAN countries. In: Lutfiana D, Anbumozhi V (eds) Disaster resilience and financing for sustainable economic growth. ERIA, Jakarta

Isaksson OHD, Simeth M, Seifert RW (2016) Knowledge spillovers in the supply chain: evidence from the high tech sectors. Res Policy 45(3):699-706. https://doi.org/10.1016/j.respol.2015.12.007

Kawasaki K, Sunami A, Ikeda Y, Huang M (2019) Japan: leveraging national regulatory reform and the economic modeling of trade agreements. In: Kingsbury B, Stewart R (eds) Contested megaregulation: global economic ordering after TPP. Oxford University Press, New York, pp 459-476

Kuroda M (2013) Science for science, technology and innovation policy. J Sci Policy Res Manag 28(1):2-3. https://doi.org/10.20801/jsrpim.28.1_2

Kuroda M, Ikeuchi K, Hara Y, Huang M (2018) Assessments of ICT policy options: the framework of input-output table linked with intangible knowledge stock. In: Mukhopadhyay K (ed) Applications of input-output model. Springer, Singapore, pp 65-110. https://doi. org/10.1007/978-981-13-1507-7_4 
Lee J, Yang J (2018) Government R\&D investment decision-making in the energy sector: LCOE foresight model reveals what regression analysis cannot. Energy Strategy Rev 21:1-15. https://doi. org/10.1016/j.esr.2018.04.003

Mahlich JC, Roediger-Schluga T (2006) The determinants of pharmaceutical R\&D expenditures: evidence from Japan. Rev Ind Organ 28:145-164. https://doi.org/10.1007/s11151-006-0010-z

Mazzola E, Bruccoleri M, Perrone G (2015) Supply chain of innovation and new product development. J Purch Supply Manag 21(4):273-284. https://doi.org/10.1016/j.pursup.2015.04.006

Ministry of Economy, Trade and Industry (METI) (2019) The trend of Japan's total R\&D expenditure, METI, The Government of Japan. https://www.meti.go.jp/policy/economy/gijutsu_kakushin/tech_ research/aohon/a17_3_1.pdf. (in Japanese)

Ministry of Internal Affairs and Communication (MIC) (2019). The summary of the investigation on science and technology, MIC, The Government of Japan. [In Japanese] https://www.stat.go.jp/data/kagak u/kekka/kekkagai/pdf/2019ke_gai.pdf

Miyagawa T, Hisa S (2013) Estimates of intangible investment by industry and productivity growth in japan. Jpn Econ Rev 64(1):42-72. https://doi.org/10.1111/jere.12000

Navarro JLA, Ruiz VRL, Peña DN (2017) The effect of ICT use and capability on knowledge-based cities. Cities 60(A):272-280. https://doi.org/10.1016/j.cities.2016.09.010

Ren S, Eisingerich AB, Tsai H (2015) Search scope and innovation performance of emerging-market firms. J Bus Res 68(1):102-108. https://doi.org/10.1016/j.jbusres.2014.04.011

Sussex J, Feng Y, Mestre-Ferrandiz J, Pistollato M, Hafner M, Burridge P, Grant J (2016) Quantifying the economic impact of government and charity funding of medical research on private research and development funding in the United Kingdom. BMC Med 14:32. https://doi.org/10.1186/s12916-016-0564-z

Suzuki K, Chida R (2017) Contribution of R\&D capital to differences in Tobin's q among Japanese manufacturing firms: evidence from an investment-based asset pricing model. J Jpn Int Econ 43:38-58. https ://doi.org/10.1016/j.jjie.2016.12.001

United Nations (UN) (2009) System of National Accounts 2008 (SNA2008), United Nation. https://unsta ts.un.org/unsd/nationalaccount/docs/sna2008.pdf

Van Der Mensbrugghe D (2013) Chapter 14-Modeling the global economy-forward-looking scenarios for agriculture. In: Dixon P, Jorgenson D (eds) Handbook of computable general equilibrium modeling, vol 1. North Holland, Amsterdam, pp 933-994

Publisher's Note Springer Nature remains neutral with regard to jurisdictional claims in published maps and institutional affiliations. 